\title{
Germanófilos brasileiros durante a Primeira Guerra Mundial: uma análise preliminar
}

Fecha de recepción: 28/8/2021 Fecha de aprobación: 04/11/2021

\section{Resumo}

No Brasil, expressar favoritismo pelos Aliados era a tônica comum entre a intelectualidade do país durante os anos da Primeira Guerra. Ainda assim, homens de letras brasileiros, de forma individual ou organizados coletivamente, quebraram a regra para publicamente demonstrarem suas simpatias à Alemanha ao longo daquele quadriênio. Debruçando-se sobre um assunto ainda pouco analisado, o presente artigo tem por objetivos: mapear de maneira preliminar quem eram esses sujeitos enquadrados como germanófilos no Brasil, e seus prováveis apoiadores; quais eram suas formas de atuação e motivações, e quais discursos construíram sobre a guerra. Através da análise de textos publicados sobretudo na imprensa da então capital federal, o Rio de Janeiro, entende-se que um dos principais intentos desses intelectuais era promover a defesa das expressões culturais da Alemanha contra os ataques dos aliadófilos brasileiros nos jornais do período. Dessa maneira, pretende-se contribuir para a recente historiografia acerca do centenário conflito, que traz a atuação dos intelectuais como primordial para a mobilização e a criação de representação em torno da conflagração. Da mesma forma, busca-se trazer novos elementos para a construção da Primeira Guerra como um conflito global, que atingiu tanto os que se encontravam em solo beligerante, quanto os que estavam a léguas de distância do front.

Palavras-chave: Primeira Guerra Mundial, guerra global, intelectuais, intelectuais brasileiros, germanófilos. 


\title{
Germanófilos brasileños durante la Primera Guerra Mundial: un análisis preliminar
}

\section{Resumen}

En Brasil, expresar favoritismo por los aliados fue una tónica común entre la intelectualidad del país durante los años de la Primera Guerra Mundial. Aun así, los literatos brasileños, individual o colectivamente, rompieron esa regla para demostrar públicamente sus simpatías por Alemania a lo largo de ese cuadrienio. Tratando un tema que aún no ha sido analizado, este artículo tiene los siguientes objetivos: mapear, de manera preliminar, quiénes fueron estos sujetos clasificados como germanófilos en Brasil y sus probables simpatizantes; cuáles fueron sus formas de actuar y sus motivaciones, y qué discursos construyeron sobre la guerra. A través del análisis de textos publicados principalmente en la prensa de la entonces capital federal, Río de Janeiro, se entiende que una de las principales intenciones de estos intelectuales era promover la defensa de las expresiones culturales en Alemania frente a los ataques de los aliadófilos brasileños. De esta manera, se pretende contribuir a la historiografía reciente sobre este conflicto centenario, que considera primordial el papel de los intelectuales para la movilización y creación de representaciones en torno a la conflagración. Asimismo, busca aportar nuevos elementos a la construcción de la Primera Guerra Mundial como conflicto global, que afectó tanto a los que estaban en terreno beligerante como a los que se encontraban a leguas del frente.

Palabras clave: Primera Guerra Mundial, guerra global, intelectuales brasileños, germanófilos.

\section{Brazilian Germanophiles over the First World War: an initial approach}

\begin{abstract}
In Brazil, the intellectuals commonly preferred the Allies over the First World War. Despite this open favouritism, some men of letters broke the rules delivering their sympathies towards the German Empire. Currently, little is known about the Brazillian Germanophiles. Therefore, this essay briefly traces who they and their supporters were, how they usually acted, their motivations, and speeches about the war. By studying their texts published in Rio de Janeiro's papers, it will be argued that one of these intellectuals' main purposes was to defend German culture from Brazilian aliadophiles' attacks on the press. It also aims to contribute to the recent historiography about this centenary conflict, showing the intellectuals' importance to the conflict's mobilisation and representation. In addition, the current essay provides new elements to
\end{abstract}


the approach of the First World War as a global conflict that engaged people from the belligerent countries as much as societies far from the front.

Keywords: First World War, global war, intellectuals, Brazilian intellectuals, Germanophiles.

\section{Intelectuais na Primeira Guerra Mundial}

A nova historiografia sobre a Primeira Guerra Mundial trouxe os intelectuais como parte dos seus principais personagens. Estudos que se dedicavam a abordar o centenário conflito sob o viés da história cultural e social paulatinamente esclareceram as diferentes funções assumidas pelos letrados nos países beligerantes (Knoles, 1968; Wohl, 1979; Rasmussen, 2014; Prochasson, 2012, Dommor, Posman, Van Djick (Ed), 2017). Sobretudo, tais pesquisas buscaram demonstrar a contribuição desses grupos para que a guerra de 1914 tivesse o signo de uma guerra total. ${ }^{1}$

A evidenciação das atividades dos intelectuais naquele quadriênio contribuiu para que a conflagração não fosse tratada como um assunto exclusivamente político-militar, do espectro de estadistas engravatados, generais condecorados e seus soldados profissionais. De maneira processual, a conflagração iniciada naquele fatídico agosto assumiu nos meses seguintes o caráter de problema urgente e concernente a todos e todas que viviam dentro das fronteiras nacionais, ao passo que o inimigo não se apresentava como uma ameaça apenas ao futuro econômico e político; era um perigo colocado contra a existência moral, os costumes, os valores, à comunidade nacional enquanto grupo de identidade cultural. Foram os intelectuais que, em sua grande parte, deram o tom dos discursos edificados para o convencimento das sociedades civis, não apenas para a aceitação da existência da guerra, mas para o seu caráter de urgência, de necessidade imperiosa.

Revestidos da autoridade dos homens de saber, esses indivíduos, de maneira bastante expressiva, puseram suas expertises, suas palavras bem articuladas, suas redes de contato, em prol das necessidades da situação de beligerância. Motivados pelas ideias nacionalistas vigentes naquele início do século XX, colaboraram para a edificação da nação em armas, cujo principal desdobramento foi a auto-mobilização dos indivíduos para os esforços de guerra, onde cada cidadão e cidadã experimentava o conflito em seu cotidiano. Produzindo materiais de propaganda nos órgãos oficiais, publicando artigos de repúdio

1 No presente artigo, nos apoiamos na definição de guerra total apresentada por John Horne (2002). De acordo com o historiador, a configuração das comunidades nacionais ao longo da segunda metade do século XIX e início do século XX, articuladas por projetos de identidades nacionais baseados em elementos não apenas políticos, mas, sobretudo, culturais, foram fundamentais para que essas mesmas comunidades se engajassem nos esforços de guerra. Dessa forma, o processo de totalização da Primeira Guerra Mundial se deu através da criação e manejo das representações sobre o conflito, apresentando o inimigo como uma ameaça ao conjunto da nação, de maneira que sua eliminação e o uso da violência irrestrita seriam não apenas toleráveis, como imprescindível. Assim sendo, as sociedades permaneceriam constante mobilizadas em torno das demandas da beligerância. 
ao inimigo nas gazetas, escrevendo textos teatrais que retratavam o opositor de maneira jocosa ou aterrorizante, compondo peças de arte que mostravam a desumanidade daquele que se encontrava do outro lado da trincheira, participando de missões diplomáticas que percorriam países aliados e neutros em busca de apoio: muitas foram as estratégias nas quais os intelectuais se engajaram com o propósito de colaborar para uma guerra que eles mesmos acreditavam como justa. $^{2}$

A consolidação dos intelectuais como objetos da historiografia sobre a Primeira Guerra Mundial contribuiu não apenas para o entendimento do processo de totalização do conflito, mas também para compreensão do seu aspecto global. ${ }^{3}$ Afinal, observa-se que não foram apenas os letrados dos países beligerantes que se movimentaram em torno da guerra. Homens longe das áreas conflagradas, salvaguardados em redações, salas de aula, escritórios e bibliotecas, sensibilizaram-se diante dos eventos desencadeados pelo conflito, reagindo e construindo ações e ideias a respeito. Tais mobilizações podem ser observadas entre os intelectuais latino-americanos, e urge conhecer quais eram suas motivações, os teores dessas ideias e ações, seus meios, seus objetivos, e em que medida dialogavam não apenas entre si, mas também com os letrados inseridos nas zonas de confronto.

Uma conflagração desencadeada entre países de onde advinham dividendos econômicos, mas, também, e desde muito tempo, paradigmas políticos e culturais caros a esses letrados, não seria tratada com indiferença por esses indivíduos. ${ }^{4}$ No Brasil, a guerra mobilizou os letrados desde os seus primeiros meses. Já em agosto de 1914, apareciam os primeiros artigos de opinião nos jornais da então capital federal, o Rio de Janeiro, e, juntamente às primeiras manifestações, surgiram as primeiras polêmicas. Os pontos de vista sobre a Primeira Guerra enquanto esta ainda se desenrolava nos campos de batalha eram por certo múltiplas em solo brasileiro, modificando-se conforme os

2 A participação dos intelectuais nos esforços de guerra se deu, inclusive, nos campos de batalha. Químicos, tradutores, geógrafos, engenheiros, dentre outros especialistas, emprestaram seus conhecimentos para os esforços militares dos seus países. Outros, ainda, engrossaram as listas de voluntários e empunharam armas em prol dos interesses nacionais: estudantes universitários, professores em idade de alistamento são algum exemplos da inserção da figura do intelectual em diferentes instâncias do conflito. Os estudos de Christophe Prochasson (2012), e Marysa Demoor, Sarah Posman e Cedric Van Djick (2017) demonstram a multifacetada participação intelectual na Primeira Guerra.

3 A compreensão de guerra global utilizada no presente artigo apoia-se, primeiramente, na análise de Hew Strachan (2010). Segundo o historiador inglês, a Primeira Guerra Mundial pode ser entendida como um evento de âmbito global, não pela escala geográfica dos envolvidos militarmente, mas, sim, pelos diferentes impactos causados aos seus contemporâneos, independente da localidade. Complementando o entendimento construído a partir de Strachan, está a percepção de Jay Winter (2014), segundo a qual o conflito deflagrado em 1914 não se restringiu à extensão das trincheiras, mas produziu reações, manifestações e interconexões múltiplas, ou seja, provocou uma infinidade de experiências históricas complementares, e não excludentes.

4 A Primeira Guerra mostrou a sua face de múltiplos ângulos na região, e não apenas econômica ou politicamente. A expansão capitalista naquele período, as inovações tecnológicas dos meios de comunicação de massa, potencializando a circularidade de bens culturais entre longas distâncias contribuíram para que, de maneira mais intensa do que outrora, os latino-americanos se vissem inseridos num amplo contexto internacional. Os intelectuais dessa região tiveram um papel importante na construção das interpretações do conflito, à medida que reagiram prontamente a ele, de maneira heterogênea. Sobre as diversas interpretações e ações dos intelectuais latino-americanos a respeito da Primeira Guerra Mundial, ver os seguintes estudos: Olivier Compagnon (2014), Eugenio Quesada Rivera (2015), María Inés Tato e Michael Goebel (2015). 
acontecimentos daqueles anos iam se apresentando, e seus diversos impactos sobre o Brasil eram sentidos, até desembocar na declaração de guerra aos Impérios Centrais, ao final do ano de 1917.

Portanto, este artigo pretende apresentar os intelectuais brasileiros que publicamente demonstraram apoio ao país que, a partir de outubro de 1917, se transformaria em inimigo do Brasil. De forma introdutória, apresentaremos esses homens, suas identidades intelectuais, seus meios de manifestação pública a respeito da guerra, seus apoiadores, objetivos e o que os incentiva, além de buscar compreender no que consistiam suas falas de apreço ao Império Alemão no contexto do conflito. A hipótese sustentada é que os desvelos direcionados àquele país pouco tinham a ver com sua campanha militar, mas, sim, com suas expressões culturais, defendidas enfaticamente por esses intelectuais.

Vale ressaltar que os germanófilos brasileiros têm recebido pouca atenção da historiografia recente acerca da Primeira Guerra. Entre 2014 e 2017, algumas obras abordaram a atuação destes indivíduos, como a do historiador alemão Stefan Rinke (2017) e a do historiador francês Olivier Compagnon (2014), onde alguns aspectos de suas expressões foram alumiados. Contudo, são abordagens realizadas dentro de obras de caráter mais geral, não havendo ainda nenhum estudo exclusivo sobre esse tema, que busque compreender o que esses sujeitos entendiam por ser simpático ao Império Alemão durante a contenda.

\section{Os germanófilos brasileiros}

É inegável que o favoritismo dos homens de letras brasileiros estava com a França, considerada a pátria-mãe da civilização moderna, genitora dos esteios culturais que embasavam suas visões de mundo. Os falantes da língua de Camões na América do Sul não ficaram imunes às investidas do Pan-Latinismo orquestrado pela França, numa expressão do seu imperialismo em solo americano, reivindicando a aproximação e a liderança em relação às antigas colônias ibéricas pelo compartilhamento de uma suposta herança cultural greco-latina (Tato, 2016: 101). Como desdobramento, parte substancial da intelectualidade do país acreditava pertencer à raça latina, numa tentativa de afastar-se das influências culturais vindas de África e dos povos indígenas que se espraiavam por toda a sociedade, pretendendo fazer da recém-reformada cidade do Rio de Janeiro uma Atenas nos trópicos. Não à toa, em março de 1915, intelectuais de renome, como Graça Aranha e José Veríssimo, ao lado de outros, não tão conhecidos, como Antônio Reis Carvalho, fundaram a Liga Brasileira pelos Aliados, entidade responsável por orquestrar o apoio da opinião pública no Brasil aos países da Entente. No discurso construído ao longo dos seus quatro anos de existência, não faltavam menções às conexões culturais entre franceses e brasileiros, o compartilhamento da raiz greco-romano, a contribuição capital da França, a seu ver, para a formação política e moral da nação brasileira (Claro Pires, 2019). 
Não eram estes, contudo, os únicos a levarem à cena pública os seus posicionamentos e predileções no que tange ao conflito. Além dos partidários da Entente, havia também os que se aferravam à neutralidade dos seus argumentos, recusando-se a apontar um favorito, o que os colocava aos olhos dos seus pares, geralmente no campo oposto do país ou bloco alvo de suas críticas naquele momento. Foi o que ocorrera com Oliveira Lima, que ganhara fama de germanófilo por tecer duras críticas à política britânica direcionada ao comércio internacional dos países neutros. 0 exemplo do diplomata demonstra, portanto, a existência de uma polarização entre a intelectualidade brasileira a respeito da beligerância, e os debates entre aliadófilos e germanófilos que dominaram as páginas das gazetas e a cena intelectual durante aqueles anos.

Em menor número, os defensores do Império Alemão mostraram-se tão dispostos quanto a sua contraparte pró-Aliados a compartilhar seus arbítrios. Simpáticos ao Reich, não se imiscuíram de irem de encontro aos seus pares de maior notabilidade, como Rui Barbosa e Olavo Bilac, para defenderem seus posicionamentos. As estratégias das quais lançaram mão foram semelhantes às dos seus opositores: artigos e ensaios alocados nas páginas dos jornais; conferências e arrecadação de donativos; associações fundadas especialmente para orquestrar suporte aos germânicos durante a guerra; publicação de livros. Isto é, falas, imagens e gestos levados ao espaço público. As motivações para tamanha mobilização em prol dos alemães, cujas aproximações culturais com os brasileiros estavam longe de ser de tamanha intensidade quanto as com a França, mostram-se, aparentemente, tão diversas quanto às estratégias utilizadas pelos seus entusiastas, e podem ser sentidas até após a assinatura do tratado de paz de Versalhes.

Como afirmado anteriormente, um estudo de maiores amplitudes ainda está por ser realizado de modo a mapear quem eram os indivíduos e grupos que se colocaram publicamente em favor do país de Guilherme II em terras brasileiras. Contudo, um levantamento inicial já traz alguns elementos relevantes a respeito desses sujeitos. Pode-se observar que exerciam uma miríade de profissões liberais: médicos, engenheiros, juristas, jornalistas, historiadores, professores, químicos, dentre outros. Alguns se ligavam ao estado brasileiro, seja por suas especialidades, seja por manterem carreiras políticas. ${ }^{5}$ Ao contrário dos partidários dos Aliados, poucos são os poetas, os romancistas, os cronistas, embora estes também apareçam no grupo. No âmbito das letras, a França reinava ainda mais absoluta entre os brasileiros: o francês era a segunda língua comumente balbuciada pelas elites e lida avidamente, um interesse alimentado por um mercado editorial, que, embora ainda restrito,

5 Algumas explicações podem ser dadas para desse aspecto apresentados pelos simpatizantes dos germânicos, sendo a principal delas diz respeito a toda intelectualidade brasileira naquele início de século, a saber, o seu aburguesamento. Os boêmios dos cafés e das redações de pasquins deram lugar aos sujeitos profissionalizados nas universidades e nas escolas técnicas, oficiados nas máquinas do estado, afinados com a ideia de ordem e progresso que dera a tônica do processo de consolidação do regime republicano no Brasil. No caso do Rio de Janeiro, então capital federal e onde se localizam os grupos e indivíduos sob análise, o programa de reforma urbana atrelado a um intenso processo civilizatório traçou as margens de uma intelectualidade que também buscava mostrar-se afinada ao racionalismo e ao asseio ligados à concepção de modernidade na primeira década do século XX. 
tinha na tradução de obras francesas um dos seus principais filões. 0 alemão, por sua vez, era pouco articulado no meio intelectual brasileiro, o que não impediu, contudo, a proliferação de suas expressões culturais, especialmente em certos nichos.

A presença das produções intelectuais de origem teutônica no país remonta desde o período colonial. No início do século XIX, missões científicas de botânicos, paisagistas, biólogos oriundos do território que, anos mais tarde, formaria a Alemanha, desembarcaram no Rio de Janeiro, estimulados pela presença da corte portuguesa na América do Sul e pelo casamento da princesa austríaca Leopoldina de Habsburgo com o herdeiro do trono luso, Pedro Bragança. No período monárquico, esse intercâmbio encontrou continuidade através da filosofia, da história, das ciências sociais e do direito, sobretudo deste último. As recém-fundadas faculdades de direito tiveram em seus quadros entusiastas da jurisprudência germânica, como Ernesto Ferreira França e Tobias Barreto (Oberacker, 1988). Portanto, até as primeiras décadas do século XX, as expressões intelectuais alemães chegaram aos brasileiros, sobretudo, através da sua produção acadêmica, e não tanto por meio das suas manifestações artísticas.

A presença de exemplares alemães nesses domínios do conhecimento pode explicar em parte o porquê do favoritismo pela Vierbund expresso em maior medida por homens cuja formação e atuação profissionais estavam circunscritas a essas áreas. Infere-se que esses indivíduos creditavam em parte aos quadros científicos alemães sua construção como intelectuais, tendo nos cientistas, filósofos, juristas oriundos daquele país, além das instituições acadêmicas, parâmetros e inspirações. Por conseguinte, ao se colocarem ao lado dos germânicos na contenda, defendiam suas orientações intelectuais, e, individualmente, a si mesmos, dos ataques perpetrados contra não apenas a campanha militar, mas, sobretudo, contra as manifestações culturais daquele país nos anos da conflagração.

Ao longo da Primeira Guerra Mundial, a transformação do inimigo como alguém desprovido de cultura foi uma estratégia comumente utilizada por ambas as partes na disputa, numa explosiva mistura de nacionalismo e darwinismo social. ${ }^{6}$ Nos países beligerantes, tais discursos contaram com os intelectuais como seus principais edificadores e difusores. Entre os Aliados, foi muito utilizado o discurso da inferioridade cultural dos alemães, quando comparados com ingleses e franceses, sobretudo esses últimos. Da França, principalmente, partiu o discurso de que a guerra era uma luta entre a civilização, representada pelos membros da Entente, e a barbárie alemã. Após a invasão pelas tropas alemães do reino da Bélgica, a desqualificação das manifestações culturais teutas consolidou-se e se espalhou na forma de material

6 A historiadora francesa Annete Becker (2015) atestou que, devido ao processo de totalização da guerra, tanto civis, quanto forças militares, ficaram reduzidos à categoria de inimigo a ser combatido, explorado ou eliminado. As teorias racistas, que já circulavam na sociedade europeia desde meados do século XIX, serviram aos discursos de subjugação e inferiorização, bem como à justificativa dada pelo uso indiscriminado da violência contra as populações que estavam do outro lado do front. 
de propaganda até onde os cabos telegráficos podiam alcançar. Consequentemente, tais falas chegaram à intelectualidade brasileira.

O tom maniqueísta foi assumido intensamente pelos intelectuais locais. A desqualificação da Kultur apresentou-se em profusão nos artigos da imprensa, nos livretos e nas conferências que tematizavam o conflito, escritos pelos que se dispuseram à defesa dos Aliados. As produções alemãs nas áreas das ciências naturais, da filosofia, da literatura, dentre outros campos do saber, foram tratadas como inferiores às francesas e inglesas, ou ainda, como meras cópias. Pelas palavras dos aliadófilos brasileiros, desenhou-se a imagem de uma Alemanha barbarizada pelo militarismo e pela ambição desmedida tanto do seu povo, quanto dos seus dirigentes, de onde nenhuma expressão cultural alinhada com os valores da civilização poderia ser criada. Já em 1914, manifestações nesse sentido eram trazidas a público, causando incômodos mesmo entre aqueles que não se viam como partidários dos alemães. ${ }^{7}$

0 desconforto, contudo, era ainda maior entre os identificados como germanófilos. Não à toa, a defesa cultural da Alemanha tornou-se um dos principais eixos do discurso desse grupo nos primeiros anos da conflagração. $\quad$ Foi da autoria do jurista e jornalista Paulo Germano Hasslocher a carta indignada, publicada pelo Jornal do Commércio, ainda em 1914, endereçada ao crítico literário José Veríssimo. ${ }^{8}$ Seu reclame era a forma depreciativa com a qual Veríssimo tratava as manifestações culturais dos alemães, tanto em seus artigos publicados naquele jornal, quanto em sua coluna no jornal $O$ Imparcial. De maneira pouco lisonjeira, Hasslocher chamava o crítico à responsabilidade por ser um "medalhão" entre a intelectualidade brasileira, e o acusava de ter desenvolvido uma "crise histérica" em relação à Alemanha e aos alemães, além de possuir uma profunda ignorância sobre a "Alemanha intelectual". Na missiva tornada pública, recusava-se a remeter a Veríssimo o nome dos alemães ilustres para rebater seus argumentos, alegando que a "imbecilidade" dos escritos do destinatário não valeria tamanho esforço. Por fim, oferecia-se para pagar a José Veríssimo aulas com um professor de alemão que pudesse ensiná-lo o que este parecia desconhecer a respeito dos germânicos (Hasslocher, 1914). ${ }^{9}$

7 Este foi o caso do desembargador Virgílio de Sá Pereira, que escreveu uma série de seis longos artigos publicados no ano de 1915 no Jornal do Commércio, sob o título "Tobias Barreto e seu germanismo". Embora criticasse a campanha dos alemães, acusando-os pelo deflagrar da guerra em razão de uma suposta ambição expansionista, Sá Pereira discordava da forma como a cultura alemã era tratada pela intelectualidade brasileira naquele momento, buscando na carreira do jurista Tobias Barreto um exemplo dos pontos positivos das produções intelectuais alemães (Pereira, 1915).

8 Paulo Germano Hasslocher (1891-1966) foi um jurista, diplomata, político e jornalista brasileiro. Nascido em Porto Alegre, no estado do Rio Grande do Sul, era filho de Germano Hasslocher (1862-1911), deputado federal de ascendência alemã, e um dos principais defensores da regulamentação da situação dos imigrantes no Brasil. Paulo Hasslocher articulou-se a outros intelectuais para a "defesa da Alemanha" durante a Primeira Guerra ao atuar na Liga Brasileira Pró-Germânia. Também foi colaborador do jornal $A$ Tribuna, destacado como um dos títulos da capital fluminense que encampou um discurso voltado para a campanha da Vierbund.

9 Paulo Hasslocher não fora o único que possuía alguma ligação com a comunidade de imigrantes alemães a reagir publicamente: nos jornais da capital federal, é possível encontrar algumas cartas levadas em reclame à forma como a parte da intelectualidade brasileira pró-Aliados construía suas ressalvas ao Império Alemão. Além das queixas, trataram de mostrar suas versões dos acontecimentos, como o frei franciscano Pedro Sinzig, nascido na Alemanha, mas naturalizado brasileiro. O religioso escreveu um 
Menos agressivo e mais eloquente, certo J. A. Almeida escreveu longo artigo publicado na primeira página do jornal $A$ Tribuna, em julho de 1915 (Almeida, 1915). ${ }^{10} \mathrm{O}$ intuito, assim como Hasslocher, era rebater outro artigo, "A cultura alemã", escrito pelo articulista do jornal Correio da Manhã, Fernão Brasil. Ao contrário do jurista, Almeida não poupou exemplos de como os alemães contribuíram para as mais diversas áreas do saber: na literatura, na filosofia, na poesia, na história, na música, na física, na química. 0 artigo ocupava quase toda a primeira página da referida gazeta, no qual Almeida descreveu em detalhes a vida intelectual dos alemães, das livrarias de Berlim à influência sobre os seus vizinhos. Endereçou sua crítica não apenas a Fernão Brasil, mas também aos "Veríssimos, Reis Carvalhos, dos Medeiros e Albuquerques, e Coelhos Netos", todos membros da Liga Brasileira pelos Aliados, e afirmou com veemência a decadência das ciências desenvolvidas em França.

Em primeiro lugar, pode-se perceber nesses discursos o que María Inés Tato (2018) classificou como "beligerância cultural". Na América Latina, a proximidade com as culturas europeias, e a identificação com os seus valores pelas intelectualidades da região, fez com esses grupos se percebessem como parte ofendida dos ataques perpetrados pelos blocos combatentes aos seus respectivos inimigos. Reagiam, como visto acima, de diferentes maneiras, manejando suas diversas argumentações de forma a defender a si mesmos e a seus interesses contra o que consideravam como agressões diretas.

Ademais, nestas e outras falas feitas ao longo do conflito de 1914-1918 pelos intelectuais brasileiros que se manifestaram favoravelmente aos germânicos, identifica-se a admiração pelo que Carlos Oberacker (1988) classificou como "Alemanha espiritual". Esta seria a representação do Império Alemão através da sua produção intelectual nos mais diversos campos do conhecimento, construindo-se para esses indivíduos a imagem de uma Alemanha vanguardista, afeita às ciências, calcada no racionalismo e afinada com os valores da modernidade. Essa imagem foi edificada ao final do século XIX, fruto do esforço de representantes da intelectualidade brasileira que não só inspiravam-se nas lições dos homens de saber germânicos, mas tomaram para si a missão de difundir a produção desses sujeitos no Brasil. ${ }^{11}$

longo artigo publicado também no Jornal do Commércio, em 1915, em que se esforçava para apresentar a imagem de um soberano pacifista do Kaiser Guilherme II, outro alvo de constantes investidas. Iniciativas como esta configuram uma demonstração de como o conflito foi apropriado e esbarrou com diferentes questões em solo brasileiro, revelando que o que estava em jogo nesses embates eram, muitas vezes, as identidades construídas.

10 Não há, até o presente momento, maiores detalhes a respeito de J. A. de Almeida. No texto endereçado ao jornal, o autor afirmava ser um "leitor cotidiano do amável e simpático vespertino"; contudo, não era usual na imprensa brasileira que leitores tivessem suas cartas expostas na primeira página, ocupando quase todo o espaço desta, com o título da sua missiva abaixo da chamada "Assuntos da guerra". Provavelmente, trata-se de um pseudônimo. Vale ressaltar que artigos pró-Alemanha publicados sob nomes falsos, assinados apenas com uma única letra ou mesmo sem declarar autoria era prática aparentemente corrente nos artigos trazidos pelo A Tribuna durante os anos do conflito. A título de exemplo, Dunshee de Abranches publicou sua tradução para o português em diversas partes naquele jornal, do livro $O$ crime do Congo, de Arthur Conan Doyle, acrescido do subtítulo Ou as barbaridades belgas, em 1915, sem assinar o texto, no entanto.

11 Foi este o caso do historiador João Capistrano de Abreu (1853-1927), admirador da escola historiográfica alemã, e responsável por traduzir para a língua portuguesa compêndios da área, que, segundo Oberacker, considerava "exemplares para os estudos dos problemas nacionais". Há ainda as iniciativas do 
Por sua vez, a guerra franco-prussiana de 1870 trouxe um momento de inflexão na difusão da cultura alemã em terras brasileiras. A surpreendente vitória alemã parece ter despertado a atenção dos intelectuais ainda não sensibilizados pela produção científica da mais nova nação europeia, e reafirmado a predileção dos já iniciados. Por outro lado, fez com que alguns apontassem uma decadência das filosofias francesas, em comparação com o que acreditavam ser a superioridade moral, intelectual e política dos germânicos.

Além da admiração pela "Alemanha espiritual”, é provável que outros elementos tenham contribuído para a construção dos argumentos utilizados pela intelectualidade pró-Império Alemão nos anos da guerra. Um deles pode ter sido o Deutschtum ou germanismo, definidos como elementos de construção de uma nacionalidade germânica em termos étnico-culturais. No Brasil, o germanismo despontou ao final do século XIX, com adesão variada entre a comunidade de imigrantes a depender de elementos socioeconômicos, segundo René Gértz (1998). O historiador identifica nas elites econômicas localizadas nos grandes centros urbanos um maior engajamento do germanismo, que também pode ser entendido como um movimento não apenas de afirmação de uma cultura germânica, mas também de sua preservação. Em outros locais da América Latina, como o Chile e a Argentina, o Deutschtum compôs parte da estratégia da propaganda germânica articulada nesses países, visando tanto combater o discurso construído pela propaganda aliada, como promover a cultura alemã, tendo nas comunidades de imigrantes seu principal ponto de difusão (Russ, 2019: 3).

A forma como se estruturou a propaganda alemã para a região durante a guerra, e uma possível aproximação entre as elites urbanas de ascendência germânica junto a esses intelectuais brasileiros, pode levar à constatação de que o germanismo tenha influenciado em certa medida esses discursos. Em território latino-americano, as comunidades de imigrantes atuaram como produtoras e distribuidoras desses materiais propagandísticos, que tinham um eminente caráter transnacional. ${ }^{12}$ Ao estudar os exemplos germanófilos

já mencionado jurista Tobias Barreto, estudioso dedicado da filosofia e do direito alemão, assim como da produção intelectual germânica de uma maneira geral. Barreto foi responsável não apenas por traduzir algumas obras para o português, mas também escreveu livros de cunho analítico como Ensaio de PréHistória da Literatura Alemã (1879) e Estudos Alemães (1880), além de uma obra sobre o Brasil escrita diretamente no idioma de Goethe, Brasilien, wie es ist (1876). De acordo com Oberacker, assim como Capistrano de Abreu, Barreto acreditava que viriam da "cultura alemã" as respostas para as mazelas brasileiras, e o modelo para o progresso intelectual e, por conseguinte, material do país. O jurista chegou a manifestar sua reprovação ao que classificou como excessiva influência intelectual da França sobre os brasileiros, responsável por sufocar o desenvolvimento de uma "cultura nacional”. Na sua percepção, uma aproximação cultural com os alemães promoveria o contrário, estimulando o florescimento da independência de raciocínio.

120 aspecto transnacional da propaganda alemã disseminada na América Latina se deu por diferentes fatores, da produção à distribuição. A Espanha, neutra no conflito, mas que contava com uma parte considerável de sua intelectualidade favorável aos germânicos, era um importante entreposto, tanto para construção desses materiais, quanto para o seu envio aos latino-americanos. Devido ao corte dos canais telegráficos pela Inglaterra ainda em 1914, o uso de uma rede wireless foi a solução encontrada pelos alemães para atingir o outro lado do Atlântico: o caminho iniciava-se em Nauen, cidade próxima a Berlim, indo até os Estados Unidos, e dali para o México. Chegando em terras americanas, contavam, como dito acima, com as comunidades de imigrantes teutos como vetores. Segundo María Inés Tato (2017), entre os sul-americanos, Buenos Aires era um destacado centro de disseminação, tendo como um dos seus elos o Rio de Janeiro. 
vistos em Argentina e no Chile, Carla Russ (2019) observa que os grupos de imigrantes dispostos a organizar os apoios manifestados em prol da campanha germânica, contaram com a adesão primordial de pessoas externas aos seus círculos. De acordo com Stefan Rinke (2017), no Brasil não era diferente, e houve uma aproximação com figuras conhecidas do espaço público brasileiro.

No contexto da Primeira Guerra, os constantes ataques perpetrados na imprensa nacional contra o Império Alemão e o que se compreendia como a produção cultural daquele país, provocou indignações entre a comunidade de imigrados e seus descendentes, como visto acima. É provável, portanto, ter existido algum tipo de articulação entre as elites urbanas teuto-brasileiras - principais aderentes ao germanismo, como apontou Gértz (1998) - e os intelectuais mencionados para a defesa do que se convencionou definir como cultura germânica. Presumivelmente, teria se constituído uma curiosa mescla entre os teuto-brasileiros e indivíduos que não tinham ligações familiares com essa comunidade, mas que, ainda assim, se dispuseram a defender a cultura germânica ao seu modo, e, por conseguinte, os que consideravam seus representantes. A presença desses elementos pode ser notada em livros e artigos de jornal durante os anos de conflito, como os do deputado Dunshee de Abranches, e como se verá mais adiante, da Liga Brasileira Pró-Germânia.

Abranches notabilizou-se no período da Primeira Guerra por ser um dos mais fervorosos partidários da Alemanha no Brasil. Louvava a organização política, social e econômica dos germânicos após a unificação de 1870, e se declarava como um profundo admirador de suas expressões culturais. Escreveu uma série de livros e livretos a respeito do conflito, buscando comprovar aquela que seria sua principal tese: a guerra era uma oportunidade ao Brasil para reorganizar-se política e economicamente, e firmar seu progresso nos novos tempos que viriam ao fim do conflito. ${ }^{13}$ Para o deputado, no entanto, o caminho para o progresso brasileiro viria a partir da aproximação com a Alemanha, detentora do que considerava a fórmula ideal para transformar um país periférico numa potência mundial. Ao longo de suas nove publicações a respeito do conflito e de seus desdobramentos em solo brasileiro, afiançou, inclusive, a relevância da Alemanha como parceira comercial e política dos interesses do país, representada tanto pelo governo germânico, quanto por suas comunidades de imigrantes. Em carta aberta endereçada ao presidente da República, Wenceslau Brás, no ano de 1916, Abranches escreveu:

\footnotetext{
No Brasil, porém, que é o caso que particularmente nos interessa, o elemento germânico, como também o teuto-brasileiro, não representa apenas o comércio intermediário, não é só o grande comissário da importação, o maior exportador, o mais hábil banqueiro, o melhor cliente e o mais liberal dos credores mercantes. É industrial, é lavrador, e, acima de tudo, em largas zonas, já chega a ser o pequeno e precioso cultivador de elementos de primeira necessidade. (Abranches, 1916: 6)
}

13 A primeira publicação de Dunshee de Abranches a respeito da Primeira Guerra Mundial - $A$ conflagração europeia e suas causas, de 1914, - foi impressa sob os auspícios da colônia alemã do Rio de Janeiro, como homenagem ao então senador Urbano Santos da Costa Araújo, futuro vice-presidente do Brasil no mandato de Wenceslau Brás (1914-1918). 
A contribuição dos imigrantes alemães viria também para o desenvolvimento social do país, segundo esses indivíduos. No ano anterior à fala de Dunshee de Abranches, era publicada no jornal $A$ Tribuna um artigo de M. Coelho Cintra, professor secundarista que assinou alguns textos na referida gazeta. ${ }^{14}$ 0 artigo, intitulado "A liga pró-aliados e a germanofobia brasileira", buscava justificar o apoio dado aos Aliados pela falta de instrução formal, o analfabetismo em grande escala, e a um "defeito de raça", proporcionado pela mestiçagem entre indígenas, africanos e portugueses, como os motivos para o apoio majoritário da população em direção aos Aliados. Segundo Coelho Cintra, a educação deficitária, a hereditariedade e o meio fizeram com que o povo brasileiro fosse afeito aos impulsos do momento, não sendo dotado de senso crítico nem capacidade de discernimento, vivendo em um "estado de misérias", "profundamente corrompidos, inaptos para tudo e desanimados para tudo!" (Cintra, 1915: 6).

Sintoma da degeneração das três raças, o suporte entusiasmado aos Aliados por parte da população do Brasil vinha por imitação, estimulada pela propaganda aliadófila que circulava, mas não apenas. Os aplausos à campanha da Entente disfarçavam, na opinião de Coelho Cintra, o receio irracional de uma correção aos seus males de origem, que adviria pela mão dos alemães. Apoiava-se os Aliados "por instinto do medo aterrador ao mais forte, por afinidades de vícios e defeitos e por tendências intelectuais de seus guias [...]", cultivando a germanofobia (Cintra, 1915). Em vão, afirmou o articulista. A vitória teuta na contenda era dada como certa e a "cura" contra, em seu entendimento, a tão maléfica composição, viria do "elemento germânico organizador", único capaz de realizar o "salvamento deste país com a grandeza das ciências, das artes, indústrias e cultura das terras" (Cintra, 1915).

As falas mostram que o apoio dado aos alemães mesclava questões suscitadas pela guerra a outras, relacionadas à própria construção da identidade nacional brasileira. 0 apoio à Alemanha justificava-se pela afinidade intelectual, pela admiração por seu rápido desenvolvimento político e econômico desde a unificação, mas também pelo entendimento que poderia figurar como um modelo para o progresso nacional. Essa corrente de pensamento foi identificada pelo jornalista Álvaro Bomílcar, na década de 1920, como "nacionalismo germanófilo". Seria uma expressão nacionalista que reafirmava a grande admiração pelos feitos alemães a partir de 1870, defendia a aproximação cultural com aquele país e acreditava ser o imigrante alemão o elemento ideal para inocular na sociedade brasileira a civilização. ${ }^{15}$ Negando os benefícios da latinidade, não raro maldizendo sua herança como uma das causas do que consideravam o atraso brasileiro, esses intelectuais afirmavam a Alemanha como ponta

14 M. Coelho Cintra era professor secundarista e, ao menos ao longo de 1915, foi contínuo colaborador do jornal A Tribuna, assinando artigos de cunho pró-Alemanha.

15 Álvaro Bomílcar (1990) classificou essa corrente nacionalista brasileira como "equivocada", ao lado do "nacionalismo raça-latina" e do "jacobinismo português". Na interpretação de Bomílcar, os nacionalistas germanófilos incorreria no erro ao adotar "o conceito malsão das raças inferiores, colocando-nos portanto a todos nós, mestiços dessas raças, na expectativa de uma absorção em nome da Estética, do Progresso e da Civilização.". 
de lança da civilização e do progresso, reivindicando uma aproximação com aquele país em benefício do futuro brasileiro, fosse através da aproximação entre os respectivos Estados, e fosse pela presença de imigrantes alemães no território nacional.

\section{Uma liga para defender a Alemanha}

Para além das iniciativas individuais de apoio público ao Império Alemão naquele quadriênio, observa-se no país manifestações do tipo coletivas. Em junho de 1915, alguns meses, portanto, após a fundação da Liga Brasileira pelos Aliados, formou-se no Rio de Janeiro sua congênere germanófila. Sua fundação deveu-se à iniciativa de dois jornalistas: Alfredo Victor Fontenelle e Djalma Leite de Castro. ${ }^{16}$

Associaram-se à Liga o meteorologista Joaquim Sampaio Ferraz, responsável pela conferência de abertura da associação; o jornalista Carlos de Laet, e os poetas Domingos Ribeiro Filho e José Oiticica. ${ }^{17}$ Num levantamento inicial sobre seus membros, percebe-se que contou com a adesão de professores da Escola Politécnica do Rio de Janeiro e do Colégio Pedro II, tradicionais instituições de ensino do país, além de militares, juristas, médicos e funcionários públicos, confirmando a tendência apresentada pelas categorias profissionais que comumente declararam apoio ao Império Alemão. Além de sócios, a entidade ganhou também congêneres, como a Liga Pró-Alemanha, fundada também no Rio de Janeiro por dois militares; e o manifesto apoio vindo de grupos localizados em outros estados da República, como o enviado por padres, acadêmicos e funcionários públicos da cidade de Ouro Preto, em Minas Gerais, que se comprometiam a "cooperar com a Liga Pró-Germânia [...] na vitória final da Alemanha nessa luta titânica travada contra ela pelo despeito e pela ambição." (Gazeta do Commércio, 20/11/1915: 2).

Os textos e boletins publicados em diferentes jornais da capital federal pareciam ser a mais relevante forma de atuação da entidade. 0 vespertino $A$ Tribuna em princípio era a sua principal plataforma de comunicação e divulgação de atividades, mas outros periódicos cumpriam também esse papel, como o Jornal do Commércio, o Correio da Manhã, o Jornal do Brasil, O Paíz e O Imparcial. Outros métodos empregados foram a realização de conferências públicas para arrecadação de donativos direcionados à Cruz Vermelha alemã; a exibição de filmes sobre a guerra, a exemplo do título "A Alemanha na guerra"; e a

16 Alfredo Victor de Fontenelle e Djalma Leite de Castro eram, ambos, jornalistas e escritores cujos nomes figuram em alguns periódicos que circulavam na capital federal. As informações sobre ambos ainda são escassas: sabe-se que Victor de Fontenelle assinava alguns artigos e publicou o livro $O$ arquivo do Diplomato $X$, enquanto Leite de Castro era dedicado à crítica teatral e tinha seu nome frequentemente publicado nas colunas sociais. Quais eram as relações desses senhores com a Alemanha e as motivações pessoais de cada um para assumir a empreitada de fundar a associação permanecem ainda nebulosas. 
distribuição de cartões postais com a imagem do Kaiser, de folhetos e outras publicações, o que demonstra que a entidade provavelmente recebia apoio material para além dos seus sócios declarados.

A Liga Pró-Germânia atuaria como uma espécie de agente de contrapropaganda, apresentando aos brasileiros outra versão do conflito. Além de isentar a Alemanha da responsabilidade pelo seu desencadeamento, a Liga edificava uma sociedade alemã amante das artes e das ciências, fruto do elevado caráter e da grandeza moral de seus componentes. Proclamavam, ainda, que as contribuições nesses campos seriam inigualáveis quando comparadas com as de qualquer outro país, e que tamanha grandeza tornava a Alemanha a liderança óbvia do mundo dito civilizado. A intenção era clara: rebater o discurso pró-Aliados que vinha sendo construído no país com o auxílio de intelectuais de renome, sobretudo daqueles reunidos na Liga Brasileira pelos Aliados. Demonstravam, dessa forma, que os germanófilos brasileiros, agindo em conjunto ou separadamente, tinham uma consonância de discursos e de objetivos.

Uma estratégia comumente utilizada para fazerem valer seus argumentos era a inversão dos papéis atribuídos aos personagens da guerra: mostrar que os bárbaros, autoritários e inimigos da cultura não eram os alemães, mas os Aliados, em especial a França. Esta era uma tática argumentativa utilizada com frequência pelos germanófilos brasileiros, com Dunshee de Abranches. Sendo assim, Liga resgatou a figura de Madame de Stäel, como ficou conhecida a intelectual francesa Germaine de Stäel, em artigo publicado na primeira página do jornal A Tribuna, em agosto de 1915, e assinado por 0. M. Teixeira. ${ }^{18} \mathrm{O}$ texto trazia aos leitores brasileiros as agruras sofridas pela escritora no seu exílio forçado no governo de Napoleão I, por escrever o livro De l'Allemagne, de 1810: todos os exemplares do livro teriam sido recolhidos; sua autora, perseguida, expulsa do país e difamada por seus próprios compatriotas. A obra, considerada responsável por levar ao meio intelectual francês do início do século XIX alguns dos principais exemplares da filosofia e da literatura produzida na região da Alemanha, foi interpretada pela Liga como uma demonstração de que até mesmo os mais altos intelectuais da França reconheciam a superioridade dos germânicos. Entre ataques aos franceses, dotados de "egoísmo" e de um "ódio e repulsão pela Alemanha", e elogios a Stäel, afirmavam:

O seu incomparável talento [de Stäel] observara que aquele povo, trabalhador e inteligente, patriota e instruído, tenaz e de vontade indomável, possuía os predicados indispensáveis para se chegar ao apogeu do progresso./Os fatos confirmaram as profecias da saudosa escritora: a Alemanha é, incontestavelmente, a nação mais poderosa do mundo, e as vitórias que ela tem alcançado nos campos de batalha e no terreno da ciência são a consequência do patriotismo e talento dos seus filhos. (Teixeira, 1915: 1)

18 Sobre O. M. Teixeira, além de integrante da Liga Brasileira Pró-Germânia, e redator de alguns de seus artigos publicados na imprensa fluminense, não se tem informações a seu respeito. 
Além de imputar aos Aliados os adjetivos que eram direcionados aos alemães, a Liga desqualificava os intelectuais que colocaram suas simpatias aos pés da Entente para se apresentarem à sociedade brasileira como os únicos detentores da "verdade". Enquanto os partidários dos Aliados apelavam para a proximidade cultural que havia entre parcela da sociedade brasileira com a França para sensibilizar os seus interlocutores, os intelectuais germanófilos reivindicavam deterem o "verdadeiro" conhecimento a respeito dos fatos do conflito, e permeavam seu discurso com um tom de revelação. A construção do argumento era dada, em geral, da seguinte forma: afirmavam a consciência de estarem indo de encontro à maioria dos seus pares (estes sendo iludidos ou simplesmente mal-intencionados em suas análises sobre a guerra), enquanto perseveravam na missão auto incumbida, animados pela certeza de estarem "do lado certo da história".

Foi este o caminho argumentativo seguido por Alfredo Fontenelle em texto publicado na primeira página do $A$ Tribuna, em julho de 1915. 0 fundador da Liga afirmava de pronto saber que "o início desse movimento que encetamos em favor da causa germânica, [...] vai nos trazer, neste começo espinhoso e difícil da organização, a antipatia dos apaixonados e o rancor dos interessados no aniquilamento da Alemanha", dando ares de sacrifício à iniciativa (Teixeira, 1915: 1). Os "apaixonados", por sua vez, eram os intelectuais aliadófilos brasileiros, e contrastavam na fala de Fontenelle com a "elite dos estudiosos", conhecedores e admiradores da Alemanha (Teixeira, 1915: 1). Seus opositores eram descritos pelo articulista como "tolos" que, ludibriados pelos inimigos dos germânicos na contenda, repetiam o seu discurso, sem reflexão (Teixeira, 1915: 1). A intenção de Fontenelle e dos demais associados era, portanto:

\footnotetext{
Restabelecer a verdade e colocar os fatos dentro das suas verídicas proporções que nós, brasileiros, amigos da Alemanha e conhecedores de suas instituições modelares, do caráter das suas gentes e da justiça da sua causa fundamos a Liga Brasileira PróGermânia [...].(Teixeira, 1915: 1)
}

E, num aceno para a comunidade alemã residente no Brasil, em seguida afirmava:

[...], que não é um movimento de simpatia de nossa parte, uma amabilidade de hospedagem, mas um franco e decidido gesto de solidariedade, uma atitude de resoluto apoio ao grande povo que a má-fé, de mãos dadas com a perfídia e a injúria, quer afastar do nosso convívio e da nossa fraternidade. (Teixeira, 1915: 1)

Tal fala demonstra a disputa de narrativas a respeito da Primeira Guerra Mundial entre os intelectuais brasileiros, mas não apenas isso. Se a Liga Brasileira Pró-Germânia apareceu na cidade com o mesmo intuito da associação próAliados, ou seja, articular as simpatias da população brasileira em direção aos alemães durante a guerra, incumbia-se também de uma segunda missão. $\mathrm{Na}$ nota que anunciava a fundação da entidade, os responsáveis afirmavam que seus objetivos eram "defender e manter bem alto as tradições de cultura e 
civilização que os inimigos da Alemanha procuram a todo o transe destruir para sempre nesta parte do continente" (Jornal do Commércio, 10/07/1915: 4). A Liga tornava público, ainda, que se empenharia "por todos os meios no seu alcance, a propaganda e a defesa do patrimônio da alta civilização que da Alemanha tem se espalhado pelo mundo e do qual o Brasil guarda, sob a proteção das suas leis, uma grande e imensa parte" Uornal do Commércio, 10/07/1915: 4). Esta pode ser tida como uma menção às comunidades de imigrantes alemães e seus descendentes no Brasil.

Em princípio, seus fundadores, Fontenelle e de Castro, não apresentam qualquer ligação com esses grupos. Destaca-se o cuidado que tiveram ao reivindicarem a nacionalidade da entidade, tanto no seu nome, quanto na afirmação de que a Liga foi fundada "exclusivamente por brasileiros" (Jornal do Commércio, 10/07/1915: 4). Mas ao se posicionar como protetora do "legado germânico" no Brasil, demonstrou em quais bases pretendia se relacionar com essa comunidade. Houve tentativas de aproximação. Em nota publicada alguns dias após a sua fundação, anunciava aos leitores do $A$ Tribuna que enviara notificações da existência da entidade ao chefe da legação diplomática do Reich no Rio de Janeiro, e à colônia alemã local. Alguns de seus membros se aproximaram, de fato, da entidade, como o já citado Paulo Germano Hasslocher, e o professor Everardo Backheuser, que, em 1916, assumiu a vice-presidência Liga. ${ }^{19}$ Em lista de associados divulgada em 1915, havia nomes que indicavam uma ascendência alemã, o que traz alguns indícios sobre o alcance da nota endereçada à comunidade germânica.

A intenção de levar aos brasileiros outra imagem da Alemanha geraria uma nova estratégia, no ano de 1916. A Liga fundou um liceu alemão, em prédio anexo ao mesmo onde funcionava o escritório da entidade, e prometia a oferta de cursos de literatura, arte e história alemãs, no que pode ser interpretado como uma tentativa de desfazer a imagem de povo bárbaro que circulava na imprensa fluminense, apresentando aos brasileiros expressões culturais produzidas em solo germânico (Jornal do Brasil, 09/05/1916). Nessa iniciativa, nota-se evidências de um desejo de não apenas defender um ponto de vista acerca do conflito de 1914, mas de traçar um plano para a divulgação das expressões culturais alemães. Dessa maneira, a ação da Liga Brasileira Pró-Germânia conecta-se com as intenções dos intelectuais brasileiros que, na virada do século XIX para o XX, almejavam ampliar o contato cultural entre alemães e brasileiros, para o benefício destes últimos. Outra possível interpretação se desenha nessa iniciativa da associação, que talvez tenha atuado como um braço do soft power alemão em terreno latino-americano, e o embrião de tentativas de estender de forma mais efetiva sua influência cultural sobre Brasil, através de uma provável aproximação com a comunidade teuto-brasileira, algo que, finda a Primeira Guerra Mundial, receberia iniciativas mais

19 Everardo Adolfo Backheuser (1878-1951) foi um engenheiro, educador e político brasileiro. Durante a Primeira Guerra Mundial, apareceu como um participante de primeira hora das atividades da Liga Brasileira Pró-Germânia: em princípio como conferencista, e no ano de 1916, como vice-presidente. 
organizadas, como a fundação da Sociedade Brasileira de Amigos da Cultura Alemã, que teria Everardo Backheuser à sua frente. ${ }^{20}$

A Liga Brasileira Pró-Germânia, contudo, não teve uma vida tão longa quanto sua contraparte favorável aos Aliados, que se manteve ativa até 1919. No ano de 1917, pouco tempo após o governo de Wenceslau Brás romper as relações com o Império Alemão, em meio à escalada que levaria à quebra da neutralidade brasileira, a entidade anunciou a sua dissolução. A razão alegada era, como de se esperar, o desejo de não se contrapor aos desígnios do estado brasileiro, que dava os primeiros passos rumo à declaração de guerra aos Impérios Centrais, em outubro daquele mesmo ano. Com exceção de Dunshee de Abranches, que publicamente demonstrou sua contrariedade com o rompimento das relações entre Brasil e Alemanha, ainda se desconhece a reação dos demais indivíduos que se dispuseram a demonstrar simpatias aos germânicos até 1917.

\section{Considerações finais}

A participação de intelectuais na Primeira Guerra Mundial se deu de forma heterogênea. Ressalta-se, contudo, sua ação fundamental na construção dos discursos que auxiliaram na legitimação do conflito perante os olhos da sociedade civil. Das letras articuladas desses indivíduos, aquele confronto, que escapava ao entendimento imediato pelas proporções assumidas, foi dotado de sentidos que o tornara inteligível aos que o vivenciavam.

Como fruto da compreensão da Primeira Guerra Mundial como um conflito global e articulado a uma guerra total, pode se observar desempenhos semelhantes entre os intelectuais que se encontravam ausentes do solo conflagrado. Caso dos brasileiros, que reagiram de maneira plural aos eventos desencadeados a partir de agosto de 1914. Embora em menor número, houve os que manifestaram em prol dos alemães, contrariando a patente favoritismo dos Aliados.

Os germanófilos brasileiros atuaram com ânimo do início do conflito até o abandono da neutralidade pelo governo de Wenceslau Brás. Fizeram-no de forma individual, como Dunshee de Abranches e o professor Coelho Cintra, ou articulados coletivamente, como a Liga Brasileira Pró-Germânia. Eram sujeitos que, em geral, pertenciam a categorias intelectuais que tinha contato com a produção cultural alemã, alguns deles creditando àquela parte de sua formação intelectual. Demonstravam algum tipo de filiação, portanto, à

20 Backheuser foi um dos fundadores da "Sociedade Brasileira de Amigos da Cultura Alemã", em 1922. A sociedade tinha como finalidade promover a cultura germânica no Brasil e fortalecer os laços culturais entre os dois países, além de "restabelecer a verdade sobre a cultura germânica", conforme indica o seu estatuto, mostrando que Backheuser deu continuidade a um dos principais objetivos da Liga PróGermânia (Muñoz, 2015). 
chamada "Alemanha espiritual". Daí, possivelmente, se depreenda a forma como disputaram a narrativa da guerra com os aliadófilos, construindo seus discursos em torno de uma Alemanha imaginada como a vanguarda da civilização moderna.

A aproximação intelectual e a admiração pelos aspectos culturais daquele país talvez não sejam as únicas explicações para o formato dado aos seus discursos naquele período. É plausível deduzir uma aproximação entre esses intelectuais e representantes das comunidades alemães de imigrantes e seus descendentes. Integrantes de uma rede transnacional que circulava a propaganda bélica do Reich, é provável que elementos desses materiais, juntamente a aspectos de uma identidade cultural germânica, tenha se mesclado às falas dos intelectuais brasileiros identificados como germanófilos. Afinal, além da presença efetiva dos teuto-brasileiros em associações como a Liga Brasileira Pró-Germânia e da provável aproximação com outras figuras intelectuais, percebe-se nesses textos um fator reagente à depreciação das expressões culturais alemães pela pena dos aliadófilos na imprensa da época.

Numa primeira análise, a defesa cultural da Alemanha aparenta ser uma das principais questões trazidas pelos germanófilos brasileiros em suas manifestações públicas. E essa intercessão não trazia a apenas a apologia às artes, aos avanços tecnológicos, e às contribuições em diferentes áreas dos conhecimentos da terra natal de Goethe, Kant e outros. Havia também o entendimento da Alemanha como modelo de desenvolvimento para a edificação do progresso brasileiro, o elogio às contribuições dos imigrantes alemães nesse sentido e, portanto, sua exaltação como elemento da civilização, e não da barbárie. Tais afirmações levavam, em alguns casos, a negação da latinidade como fator positivo na conformação da identidade brasileira, vista como componente do atraso do país.

Seja como for, a observação inicial da atuação dos germanófilos no Brasil torna possível entender que a Primeira Guerra Mundial trouxe reações diversas, despertou diferentes raciocínios e serviu de ponto de partida para articulações sociais múltiplas durante e mesmo após o seu término oficial. 


\section{Bibliografia}

" De Abranches, D. (1916). Ainda a Black List 1916. Imprensa Nacional.

" De Almeida, J. A. (1915). Em torno de um artigo do Sr. Fernào Brasil. A Tribuna. $22 / 07 / 1915$

" Becker, A. (2015). The Great War: World War, total war. International Review of the Red Cross, n. 97.

" Bomílcar, A. y de Oliveira, L. (1990). A questão nacional na Primeira República. Brasiliense.

" Claro Pires, L. (2014). Intelectuais nas trincheiras. Appris.

"Coelho Cintra, M. (1915). A liga pró-aliados e a germanofobia brasileira. A Tribuna, 25/08/1915.

" Coisas da Guerra. 20/11/1915. GAZETA DO COMMÉRCIO.

" Compagnon, O. (2014). O adeus à Europa. Rocco.

" Demoor, M., Posman, S. e Van Djick (ed.). (2017). The intellectual response to the First World War. Sussex Academic Press, 2017.

" Gértz, R. (1998). Germanismo. GÉRTZ, R. O perigo alemão. Ed. Universidade/UFRGS

" Hasslocher, P. G. (1914). Sr. Dr. José Veríssimo. Jornal do Commércio. 15/10/1914

" Horne, J. (2002). Introduction: mobilizing for 'total war. Horne, J. (ed.). State, society and mobilization in Europe during the First World War, Cambridge University Press.

"Knoles, G. (1968). American Intellectuals and World War I. The Pacific Northwest Quarterly, n. 4.

" Liga Brasileira Pró-Germânia. 09/05/1916. JORNAL DO BRASIL.

" Liga Brasileira Pró-Germânia. 10/07/1915. JORNAL DO COMMÉRCIO.

" Muñoz, P. (2015). À Luz Do Biológico: Psiquiatria, Neurologia E Eugenia Nas Relações Brasil-Alemanha (1900-1942. Tese de doutorado apresentada à Casa de Oswaldo Cruz FIOCRUZ. Inédita.

" Oberacker, C. (1988). Os intelectuais brasileiros e a cultura alemã. 1890-1930. Jahrbuch für die Geschichte von Staat, Wirtschaft und Gesellschaft Lateinamerikas, n. 25.

"Prochasson, C. (2012). Intellectuals and Writers. HORNE, J. (ed.), A Companion to World War I, Wiley-Blackwell.

"Quesada Rivera, E. (2015). Defendemos a Alemania con el mismo derecho que La Información lo hace con los Aliados: germanofilia durante la Gran Guerra (1914-1918). Revista Reflexiones, n. 1.

" Rasmussen, A. (2014). Mobilising minds. Winter, J. (ed.), The Cambridge History of the First World War, v. 3, Cambridge University Press.

" Rinke, S. (2017). Neutrality under pressure, 1914-1917. Latin America and the First World War. Cambridge University Press.

" Russ, R. (2019). Persuasive identities: German propaganda in Chile and Argentina during the First World War?. National Identities, n.20.

"Sa Pereira, V. (1915). Tobias Barreto e o germanismo. Jornal do Commércio, 02/05/1915 
"Strachan, H. (2010). The First World War as a Global War. First World War Studies vol. 1.

" Tato, M.I. e Goebel, M. (2015). Making sense of the war (Latin America). 1914-1918 Online International Encyclopedia of the First World War, https://encyclopedia.19141918-online.net/article/making_sense_of_the_war_latin_america.

"Tato, M. I. (2017). Fighting for a lost cause? The germanophile newspaper La Unión in neutral Argentina, 1914-1918. War in History, https://doi. org/10.1177/0968344516682043

" Tato, M.I., (2018). Fighting the war from the periphery: Latin America and WWI. Palestra proferida no congresso Tempos de Violência. Fundação Casa de Rui Barbosa, RJ, 20 junho.

" Tato, M.I. (2016). The Latin American intellectual field in the face of the First World War: an initial approach. Pla, X., Fuentes, M. y Montero, F. (eds.). A Civil War of Words. The cultural impact of the Great War in Catalonia, Spain, Europe and a glance to Latin America. Peter Lang AG, Internationaler Verlag der Wissenschaften.

"Winter, J. (2014). General introduction. Winter, J. (ed.). The Cambridge History of First World War volume I Global War. Cambridge University Press.

"Wohl, R. (1979). The generation of 1914. Harvard University Press.

\section{Sobre a autora}

Livia Claro é Mestre em História Política pela Universidade do Estado do Rio de Janeiro. Atualmente, é doutoranda em história social no Programa de Pós-Graduação em História Social pela Universidade Federal do Rio de Janeiro, com projeto pesquisa acerca dos intelectuais germanófilos brasileiros durante a Primeira Guerra Mundial. Suas áreas de investigação são: Primeira Guerra Mundial, história social e cultura da guerra; história política; história dos intelectuais. É autora do livro Intelectuais nas Trincheiras, publicado pela editora Appris, em 2019.

0000-0003-2870-3149

\section{Sobre la autora}

Livia Claro es Magíster en Historia Política por la Universidad del Estado de Río de Janeiro. Actualmente es doctoranda en historia social en el Programa de Posgrado en Historia Social de la Universidad Federal de Río de Janeiro, con un proyecto de investigación sobre los intelectuales germanófilos brasileños durante la Primera Guerra Mundial. Sus áreas de investigación son: Primera Guerra Mundial, historia social y cultura de la guerra, historia política e historia de los intelectuales. Es autora del libro Intelectuais nas Trincheiras, publicado por Appris en 2019.

\section{About the author}

Livia Claro holds a master's degree in Political History from the State University of Rio de Janeiro. She is currently a PhD candidate in social 
history at the Postgraduate Program in Social History of the Federal University of Rio de Janeiro, with a research project on Brazilian Germanophile intellectuals during the First World War. Her areas of research are World War I, social and cultural war history, political history and history of intellectuals. She is the author of the book Intelectuais nas Trincheiras, published by Appris in 2019. 